\title{
CFD analysis of steam superheater, transient state
}

\author{
Mariusz Granda ${ }^{1, *}$, Marcin Trojan $^{1}$, and Jan Taler ${ }^{1}$ \\ ${ }^{1}$ Institute of Thermal Power Engineering, Cracow University of Technology, Poland
}

\begin{abstract}
Nowadays, industry requirements referring to the optimization, not only demand better efficiency or durability but also the lower total cost of the project. Maximum temperatures, allowable stress and economics determine materials used during the engineering process. Moreover, different materials in different parts of superheater can be used. Regarding the steady-state, calculations can be derived without major difficulties but transient-state is a much more complex issue, where Computational Fluid Dynamics can be applied. CFD as an engineering tool, that gives a better understanding of the problem, is more and more popular during the optimization process. Appropriate knowledge about heat transfer, fluid dynamics, finite element method is required to find the solution to the given question. The paper presents a CFD analysis of the transient-state of the steam boiler superheater when attemperator is running. Temperature distribution of the steam, flue gas and maximum wall temperature were determined.
\end{abstract}

\section{Superheater design}

Steam superheater is located at the high temperature flue gas zone, so the oxidation resistance and the maximum operating temperature value determine materials from which these kind of devices should have been made [1,2]. During the design process, according to above criteria, only the economical and reliable configuration should be taken into account. Total parallel flow configuration (Fig. 1.a) allows using less demanding materials, although it is necessary to increase the total heat exchange surface by about $7 \%$. The total counter flow configuration (Fig. 1.b) gives the reduction of the heat exchange surface by $7 \%$, although requires much more sophisticated materials [1]. The above comparison is the compromise between the required surface of such accessories limited by the dimensions of the boiler and steam temperature requirements and in consequence material temperature limitations [1]. Also combined flow configuration (Fig. 1.c) can be applied where median metal temperatures occur and where there are no limitations due to the boiler dimensions. Also, it should be evaluated which elements of the superheater are exposed to the higher and which elements are exposed to the lower temperatures. In sub and super-critical power boilers, the costs of high-alloy steels are very high, so different materials in a different temperature range should be applied. According to the literature [1], the case of a two-passes superheater (Fig. 1.d) shows that the "worse" material can be selected in the case of tube No. 1 and "better" for tube No. 2. To avoid application of different materials, design of superheater, where the next passes are alternately charged with higher and higher temperatures, should be taken into account (Fig. 1.e). An experienced engineer should choose the appropriate solution to meet the design requirements.

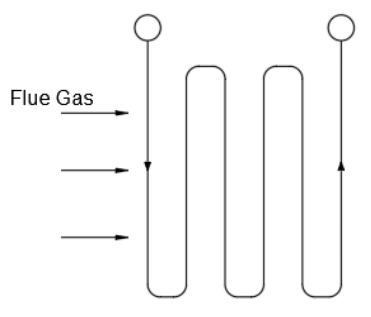

Fig. 1.a. Total parallel flow configuration

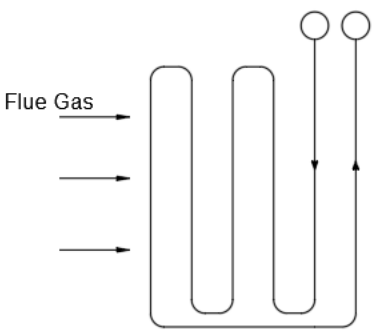

Fig. 1.c. Combined flow configuration

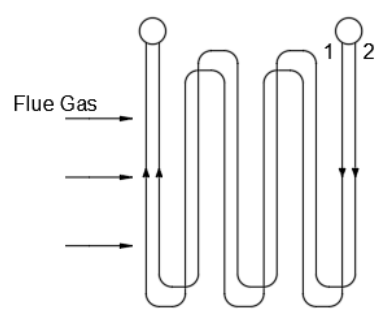

Fig. 1.e. Two pass configuration

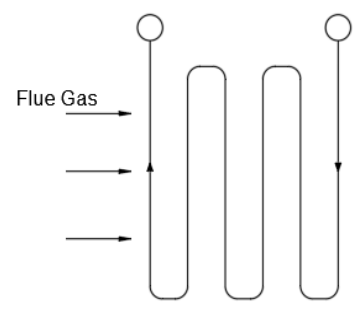

Fig. 1.b. Total counter flow configuration

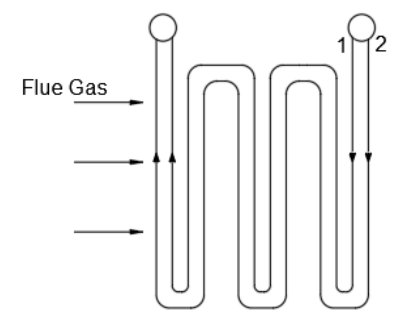

Fig. 1.d. Two pass configuration

\footnotetext{
Corresponding author: mariusz.granda@pk.edu.pl
} 


\section{Steam temperature control}

The above paragraph shows how important the design process of such accessories like superheater is. Such element of the steam boiler improves Rankine's cycle efficiency by achieving higher steam temperatures [1] [2] so that precise steam temperature control and adjustment are necessary to avoid failures due to excess of the material temperature. In addition, monitoring of this parameter is also required, especially during transient states, when uneven temperature fluctuations may occur. In drum-type boilers, where steam output is the result of the firing rate, temperature depends on design factors like: total surface quantity and ratio of convection to radiant surface. In sub and super-critical power boilers, where drum boiler doesn't exist, steam temperature is feed water flow rate and firing rate dependent, however in both situations other operating variables such as excess air, fuel composition, heating surface cleanliness, feed water temperature and burner adjustment can't be neglected [1]. The most common way of steam temperature regulation is an attemperation, where temperature control range is higher in comparison with other methods, however it is not recommended to exceed the amount of injected water, by more than $8 \%$ of the current steam output [2]. Also quality control of high purity water is needed. Another important issue is the thermal shock when cold water is introduced, by the spray action, to the throat of a venture section. Steam rapidly mixes with sprayed water and which means high drop of steam temperature. In order to avoid the thermal shock, special sleeve must be installed.

\section{Steady state analysis}

The object of the investigation, is the one row of the second stage of superheater of OP210M steam boiler that consists of three tubes (Fig. 2). The wall of the tubes is smooth. As for the environment, flue gas has been taken into account. Control volume is restricted by the boiler dimensions. So the height of superheater varies from 6 to $7 \mathrm{~m}$. Length of the control volume has approximately 1,6 $\mathrm{m}$. Only the width is equal to the transverse graduation. Steel properties are temperature dependent (Fig. 3). Operating conditions like pressure, temperature (Table 1) during the steady state, were derived directly from calculations, based on measurement. Also the flue gas composition was given and implemented to the simulation. Steady state analysis is the basis to the transient state, however, changes in the flue gas, because of the negligible influence, were considered as steady. Transient state is much more complex issue, so that, to make numerical calculation during unsteady state feasible, discrete model should be accurate and as simple as possible. In terms of that and at the basis of the fluid mechanic and finite volume method theory, discretization of the boundary layer should be prepared properly. In this case, only fully turbulent flow occurs, so the most important is dimensionless $\mathrm{y}+$ parameter that is very useful for velocity profile description $[3,4,5]$. Another important criterion is the mesh quality, where poor mesh orthogonality has enough influence, to make solution of the simulation distant from the reality [6]. Others factors like expansion factor and aspect ratio in tube flows are not strong enough. In this particular case two mesh have been generated (Table 2). In both situations $y+$ is the same and the only difference is number of inflation layers in steam domain in order to improve mesh orthogonality (Fig. 4,5).

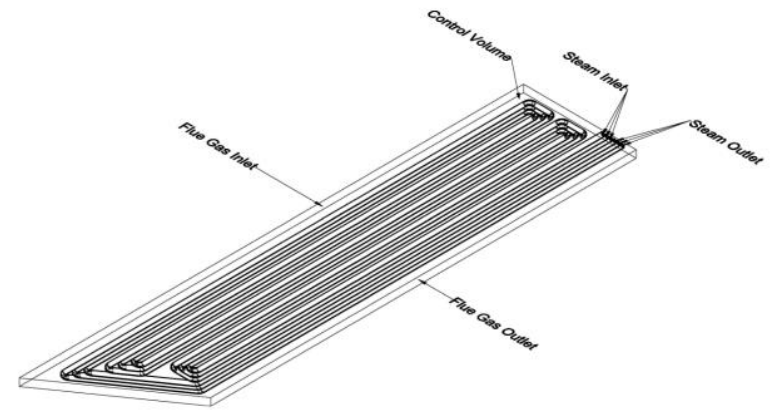

Fig. 2. Geometry of the one row of second stage of superheater of OP210M steam boiler

$$
\Delta \quad \lambda[\mathrm{W} /(\mathrm{mK})] \longrightarrow \mathrm{Cp} * 10 \mathrm{e}-1[\mathrm{~J} /(\mathrm{kgK})] \multimap \rho\left[\mathrm{kg} / \mathrm{m}^{\wedge} 3\right]
$$

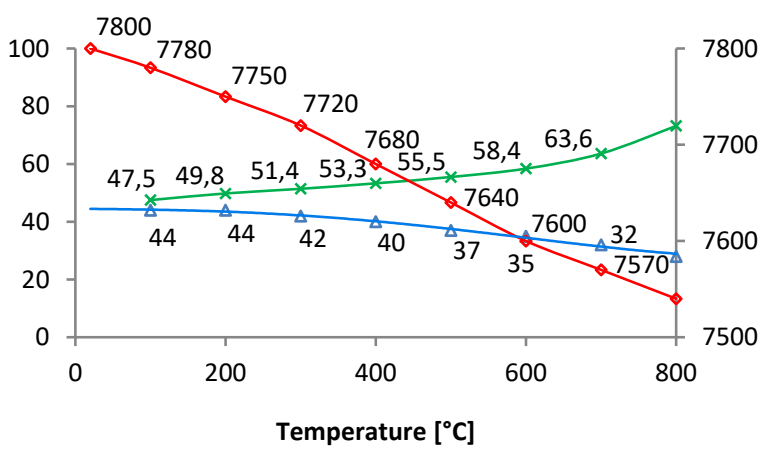

Fig. 3. Steel 12X1MF properties

Table 1. Operating conditions during the steady state

\begin{tabular}{lccccc} 
& $\begin{array}{c}\text { Steam } \\
\text { Inlet }\end{array}$ & $\begin{array}{c}\text { Steam } \\
\text { Outlet }\end{array}$ & $\begin{array}{c}\text { Flue Gas } \\
\text { Inlet }\end{array}$ & $\begin{array}{c}\text { Flue Gas } \\
\text { Outlet }\end{array}$ \\
\hline Temperature [oC] & 432,75 & 525,54 & 1006,55 & 724,30 \\
Mass Flow [kg/s] & 49,47 & 49,47 & 62,74 & 62,74 \\
Pressure [MPa] & 9,64 & 9,64 & 0,101325 & 0,101325 \\
\hline
\end{tabular}

Table 2. Mesh properties

\begin{tabular}{lll} 
Mesh number & 1 & 2 \\
\hline Program & Ansys Mesh & Ansys Mesh \\
Element Order & Linear & Linear \\
Element Size & $0,02 \mathrm{~m}$ & $0,02 \mathrm{~m}$ \\
Sweep size & $0,03 \mathrm{~m}$ & $0,02 \mathrm{~m}$ \\
Growth Rate & Default $(1,2)$ & Default $(1,2)$ \\
Inflation (Steam) & & \\
$\quad$ First Layer Height & $8,3 \mathrm{e}-6 \mathrm{~m}$ & $8,3 \mathrm{e}-6 \mathrm{~m}$ \\
$\quad$ Maximum Layers & 8 & 10 \\
$\quad$ Growth Rate & 1,6 & 1,6 \\
Inflation (Flue Gas) & & \\
$\quad$ First Layer Height & $5 \mathrm{e}-4 \mathrm{~m}$ & $5 \mathrm{e}-4 \mathrm{~m}$ \\
$\quad$ Maximum Layers & 3 & 3 \\
$\quad$ Growth Rate & 1,4 & 1,4 \\
Nodes & 1554174 & 2749737 \\
Elements & 2337906 & 4089969
\end{tabular}




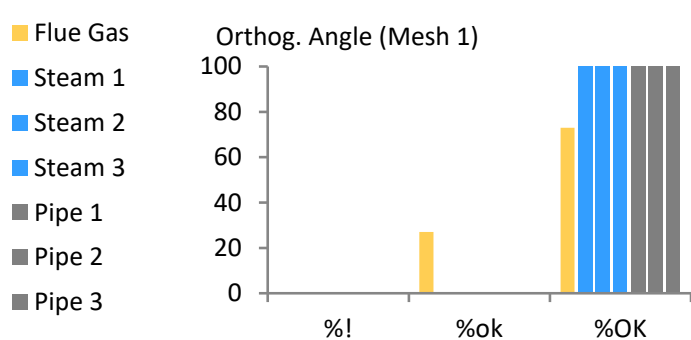

Fig. 4. Percentage of elements meeting the criterion of the mesh orthogonality (Mesh 1)

$$
\begin{aligned}
& \text { Flue Gas } \\
& \text { - Steam } 1 \\
& \text { - Steam } 2 \\
& \text { n Steam } 3 \\
& \text { - Pipe } 1 \\
& \text { - Pipe } 2 \\
& \text { - Pipe } 3
\end{aligned}
$$

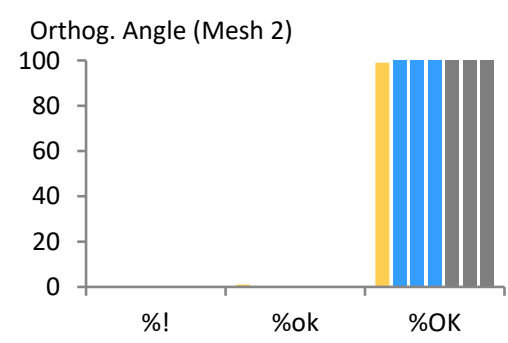

Fig. 5. Percentage of elements meeting the criterion of the mesh orthogonality (Mesh 2)

During the steady state simulation, bulk temperature at the whole outlets have been measured, as well as convergence of continuity, momentum, energy equations. Calculation has been carried out until average temperature at the outlet was met with experimental data (Table 1). Based on assumption to the mesh quality, better results should have been given by "Mesh 2" discretization, what had been proven in case of average temperature over whole Steam Outlets and Flue Gas Outlet (Fig 6, 7).

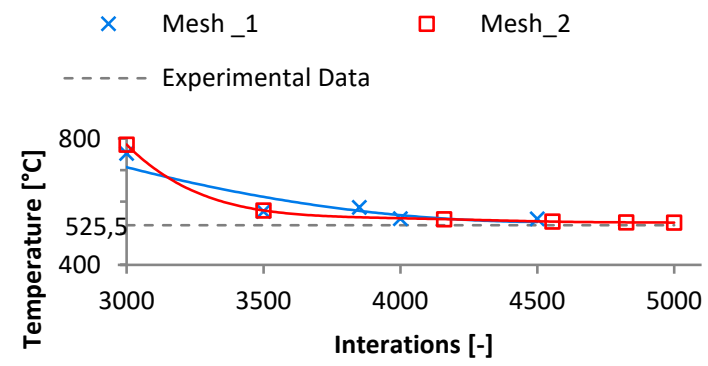

Fig. 6. Convergence of the average bulk temperature over whole Steam Outlets

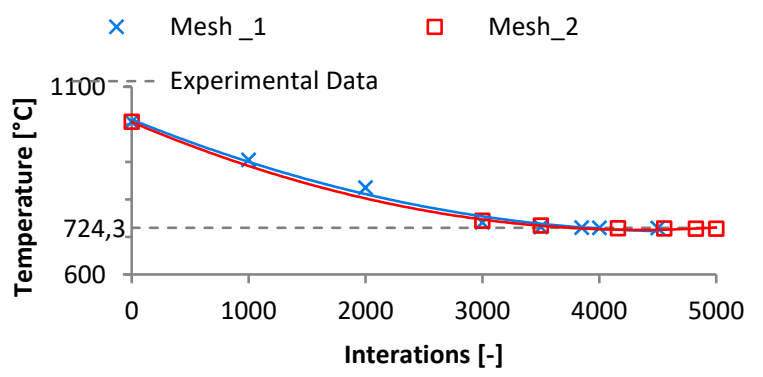

Fig. 7. Convergence of the bulk temperature at the Flue Gas Outlet

\section{Transient state analysis}

The major difficulty of transient state simulation is the choice of the time step. There are two different approaches in terms of that. First, called "pseudo transient" approach can be carried out, where time step is big enough and CFL (Courant-Fredirchs-Lewy) condition wouldn't met. However, it is worth mentioning, that fluctuations or changes of phenomena during that long time step will not be considered. Also each time step must be considered as steady state problem, so much more iterations need to be carried out [7]. Second one is the approach where Courant number is below one. That means that time step is small enough to consider all fluid changes within nodes of the mesh. According to the investigation, due to the high speed of the steam, the major changes in the axial direction occur and the time step have been set up from $0,001-0,0005 \mathrm{~s}$ to keep up with all of the changes in that direction. However, the flow is fully turbulent, and changes in radial direction also occur, where, distance from the nodes, especially near to the wall is small enough to obtain Courant number below one, so the convergence criteria were followed to keep the solution stable and accurate.

\section{Results}

After simulation, at the post-processing step, in order to understand superheater cooling process, the nonstationary temperature field have been investigated. To show temperature changes during 16 seconds of attemperation, 54 temperature probes have been defined, 18 for each tube: at the beginning, in the middle, in the end of each pass (Fig. 8).

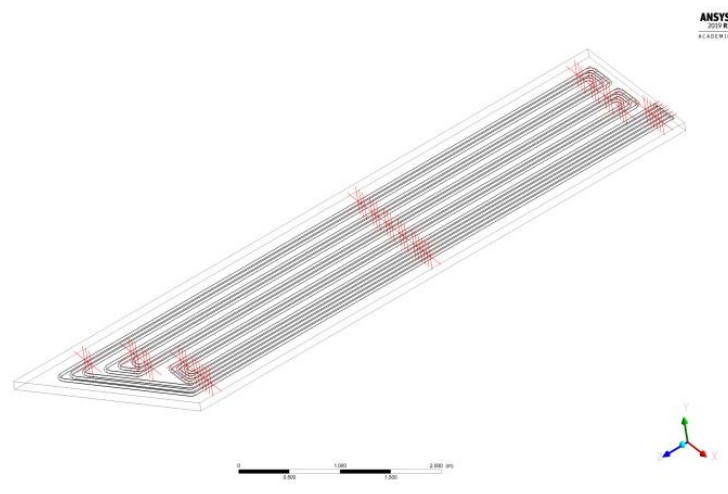

Fig. 8. Location of temperature probes

To show highest possible temperatures and in terms of that, material limitation, only outer tube surface was taken into account. $(0.1 \mathrm{~mm}$ deep into the wall to avoid approximation errors at the fluid-solid domain). In addition, the maximum temperature value was followed for each tube separately. To compare temperature distribution with the assumptions resulting from the design, according to the literature, appropriate line charts were generated (Fig. 9-16). 


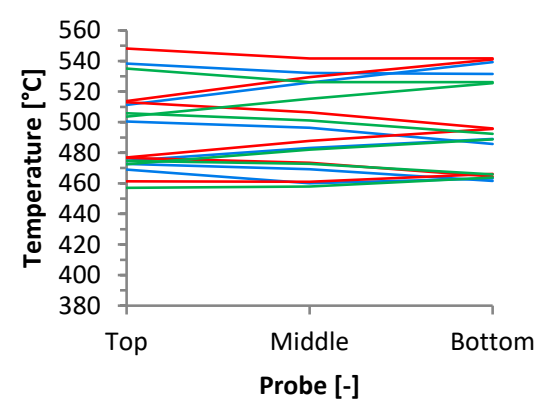

Fig. 9. Temperature distribution of each tube across the passes at the beginning of the work of attemperator
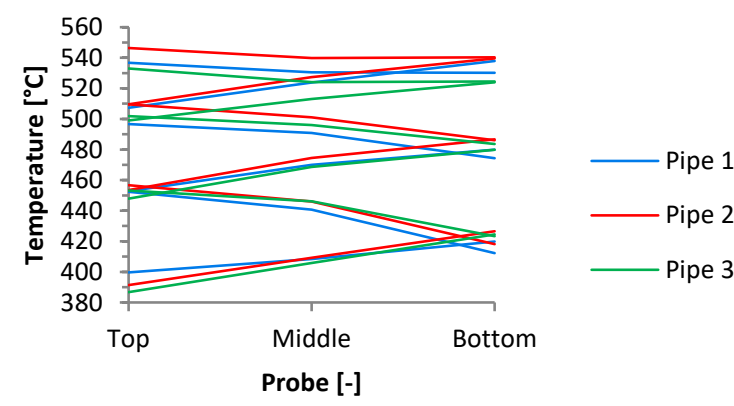

Fig. 10. Temperature distribution of each tube across the passes at 10 th second of the work of attemperator
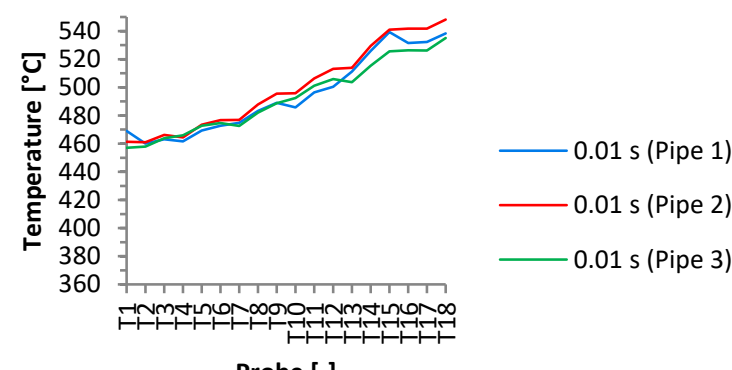

Probe [-]

Fig. 11. Comparison of temperature distribution along the tubes at the beginning of the work of attemperator

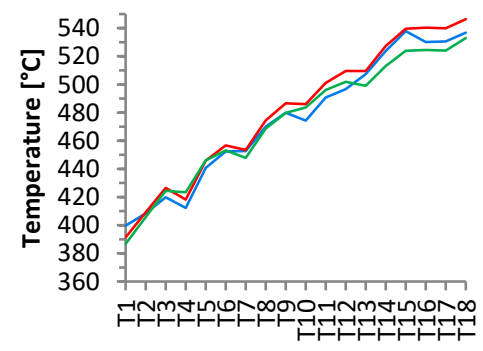

- 10 s (Pipe 1)

$10 \mathrm{~s}$ (Pipe 2)

$10 \mathrm{~s}$ (Pipe 3)

Probe $[-]$

Fig. 12. Comparison of temperature distribution along the tubes at the 10th second of the work of attemperator

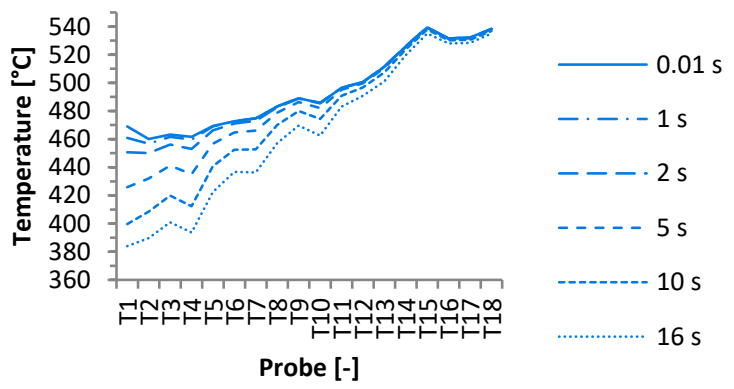

Fig. 13. Temperature distribution along the Tube No. 1 during the attemperation

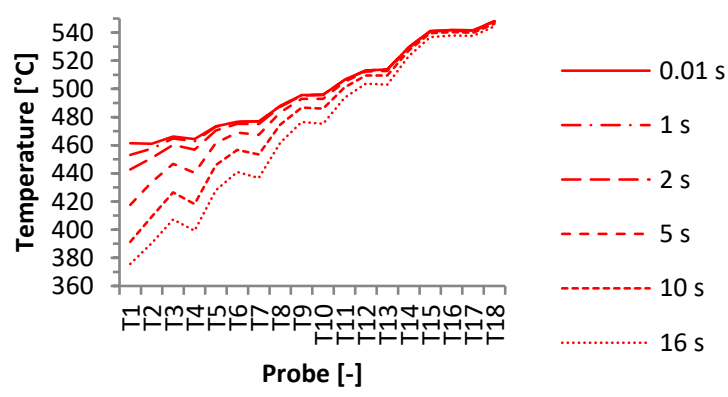

Fig. 14. Temperature distribution along the Tube No. 2 during the attemperation

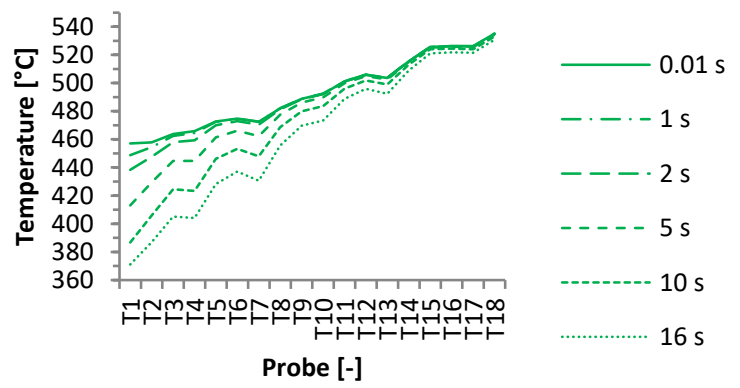

Fig. 15. Temperature distribution along the Tube No. 3 during the attemperation

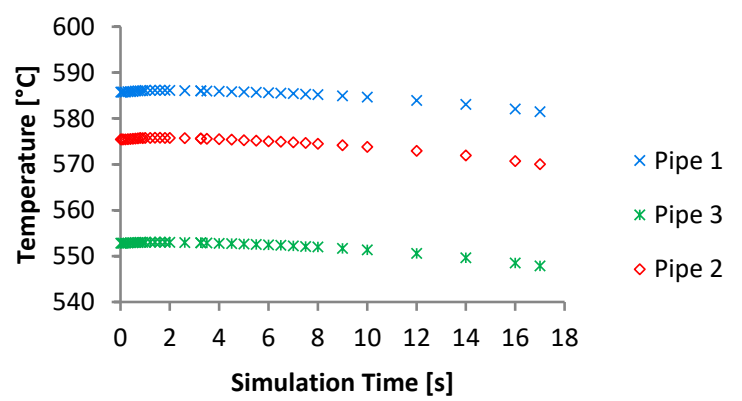

Fig. 16. Comparison of temperature distribution along the tubes at the beginning of attemperation 


\section{Conclusions}

It is known that the steam plays the key role due to cooling of the walls of superheater tubes during its operation. With the reference to the theory about steam, superheating process and steam temperature control, and according to the results of the simulation, where non-stationary temperature field was investigated, the temperature distribution in subsequent passes of each tube at the beginning as well as in the 10th second of operation of the attemperator (Fig. 9-10) indicates that Tube No. 2 works at the range of higher temperatures in relation to the outer tubes. The only inconsistency can be found at the inlet section in reference to the tube No. 1 . The reason of that irregularity is its exposition to a higher temperature flue gas zone. In addition, Figures 9-10 show that design of superheater, that is assembled from more than one tube, needs in-depth analysis of the temperature field in order to apply different materials in a different zones. The theory shows that tube No. 1 (Fig. 1.e) should work under lower temperatures. The investigation concerns a superheater which consists of three tubes. The first tube should have a lower temperature compared to the third tube, while in the subsequent passes, a higher temperature can be observed in that tube, which in the current pass is closer to the combustion chamber (at the higher temperature flue gas zone). However, the average operating temperatures of both external tubes are very close to each other, in contrast with the average temperature of the second tube, whose temperature is distinctively higher, and that difference increases towards the higher flue gas temperatures. The further investigation of the non-stationary temperature field, shows how insensible, in this type of heat exchangers, the process of cooling is. Even after 16 seconds of the attemperation, temperature of the final tube sections drops only a few $\mathrm{K}$, in the middle section from 30 to $40 \mathrm{~K}$, near the inlet from 40 to $90 \mathrm{~K}$ (Fig. 13-15). The change of the maximum temperature value during the cooling process (Fig. 16) shows how long some parts of the superheater work under high temperature and how slow the cooling process is. This is the major limitation due to material oxidation in the material selection process. Highest temperature values were located at the front of the superheater where still hot flue gas zone occurs. Despite the fact that the tube in the middle works at the higher temperature range than others (5-10 K), the maximum temperature has been recorded for tube No. 1 and it is higher by about $10 \mathrm{~K}$ in comparison to the values registered in case of the Tube No. 2. What is observed is that the transient state of the work of the superheater does not really affect the temperature distribution along the tubes and the discrepancy between them as a result of the tube layout as well. To confirm the above relationship, remaining transient states should be considered. It will limit the consideration of material application to a steady state only. CFD simulation is an important tool supporting the design or the optimization process. With the correct approach to the modelling, it possible to understand all the physics occurring during the device operation.

\section{References}

1. J.B. Kitto, S.C. Stultz, Steam its generation and use (The Babcock \& Wilcox Company, Barberton, 2005)

2. P. Orłowski, W. Dobrzański, E. Szwarc, Kotty parowe (Wydawnictwo WNT, Warszawa, 1979)

3. M. Granda, Steady state CFD analysis of heat transfer coefficient in pressurised tubes of superheater of OP210 steam boiler, MATEC Web of Conferences 240, 05008, (2018)

4. D. Taler, Obliczenia $i$ badania eksperymentalne wymienników ciepła I (Wydawnictwo PK, Kraków 2016)

5. N.M.C. Martins, N.J.G. Carriço, H.M. Ramos, D.I.C. Covas, Velocity-distribution in pressurized tube flow using CFD: Accuracy and mesh analysis (Elsevier, Lisbona, 2016)

6. CFX-Pre User's Guide (2016)

7. O. Zikanov, Essential Computational Fluid Dynamics (John Wiley \& Sons, Inc. New Jersey, 2010) 